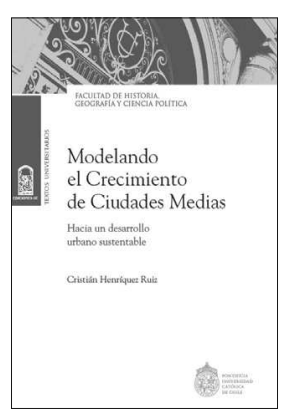

\title{
Cristián Henríquez Ruiz. Modelando el crecimiento de ciudades medias. Hacia un desarrollo urbano sustentable
}

\author{
Santiago de Chile: Ediciones de la Universidad Católica de \\ Chile, 2014. 314 p. \\ ISBN: 978-956-14-1470-9
}

Maria Encarnação Beltrão Sposito ${ }^{1}$

Qual é o paradigma dominante para a evolução das cidades no século XXI?

Com esta questão e destacando seus desdobramentos, bem como as múltiplas possibilidades de respondê-la, Jonathan Barton, diretor del Centro de Desarollo Urbano Sustentable (CEDEUS) redige o prólogo do livro de Cristián Henríquez Ruiz, intitulado Modelando el crescimiento de ciudades medias. Hacia un desarollo urbano sustentable.

Após este prólogo que contribui para sensibilizar o leitor para o tema, de um modo geral, e para a abordagem do autor, de modo particular, segue-se o livro de Henríquez dividido em seis capítulos antecedidos por uma introdução e sucedidos pelas referências bibliográficas.

Desde a introdução, o autor, de modo muito apropriado, já destaca que a maioria dos 'desequilíbrios ambientais' têm origem nos atuais processos de crescimento econômico e demográfico, muito mais consumidores de recursos naturais, incluso de energia.

A busca do autor é pela superação dos estudos setoriais, cujas visões parcelares

Departamento de Geografia, Universidade Estadual Paulista - UNESP (Brasil).

E-mail: mebsposito@prudenet.com.br inviabilizam, de um lado, diagnósticos mais integrados e, de outro, programas, políticas e ações capazes de superar os impasses que vivemos no período atual.

A integração das dimensões econômica, social, ecológica e ambiental é, então, sua proposta, por meio de formulação de modelo para avaliar a sustentabilidade do sistema urbano.

Sabemos todos que a palavra "sustentabilidade" tão em voga, tem conteúdo polissêmico. Ela tem feito parte dos discursos de políticos, cujo objetivo primeiro é serem eleitos; integram os documentos das principais agências nacionais e internacionais preocupadas, mais ou menos, com o futuro do mundo; é adotada em livros didáticos e cartilhas que buscam reorientar a educação ambiental no período contemporâneo; do mesmo modo esta palavra é objeto de pesquisas e de reflexões por parte daqueles que desejam dotála de conteúdo conceitual.

Com tamanha energia política e científica vertendo sobre ela, tal palavra tanto pode esvaziar-se como ganhar contornos mais precisos e se consolidar como narrativa importante para a leitura do mundo e para a ação sobre ele.

Penso que o livro de Henríquez contribui para esta segunda opção. O autor demonstra capacidade de tornar a expressão um instru- 
mento metodológico que valoriza o estudo de dimensões espaçotemporais da sustentabilidade urbana.

Como ele conseguiu fazer isso? Encontrou meios e fontes para captar, sistematizar e analisar o que extrai de sistemas de informação geográfica, formas de percepção remota, trabalho de campo e por meio de uma ecologia da paisagem.

Seu objetivo é desenvolver modelação e simulação ambiental do crescimento urbano, navegando no âmbito da Geografia Urbana e da Ecologia Urbana.

Seu enfoque é multiescalar e multidimensional, para perceber e analisar os efeitos ambientais do uso do espaço urbano, olhando para trás e para frente no tempo. Parece fácil fazer isso, quando se supõe a articulação entre tantos níveis como uma proposta ou como uma possibilidade, mas ele fez algo mais difícil que é um modelo que pode ser aplicado e, portanto, é passível de ser colocado em prova. Vejamos, capítulo por capítulo, como o autor levanta hipóteses, desenvolve raciocínios, formula ideias e propostas, e, assim, coloca efetivas teses sobre o tema em análise.

O primeiro capítulo, chamado "El problema ambiental de la urbanización", é aquele sobre o qual me deterei mais nesta resenha, pelo seu caráter de contextualização e fundamentação da proposta contida no livro.

Nele, o autor aborda as políticas internacionais de desenvolvimento sustentável, começando pela Conferência das Nações Unidas de Estocolmo, em 1972, quando se inaugura a preocupação mundial com a questão ambiental e lembra o certame do Rio de Janeiro, 20 anos depois, quando se firmaram compromissos mais sérios acerca da sustentabilidade, compondo a Agenda 21. Em Johanesburgo, em 2002, o tema voltou em pauta e muitos encontros ocorridos refletem que a preocupação com o meio ambiente ganha cada vez maior magnitude, mostra o autor, ainda que nem sempre, nem em todos os países, isto tem se refletido imediatamente em medidas sérias e eficazes, sendo, ainda excepcional a posição da União Europeia no respeito à nova agenda.
Indicadores de meio ambiente ou de sustentabilidade ambiental tem sido formulados e são iniciativas importantes, mas no Chile, eles são ainda usados incipientemente, sobretudo em se tratando de cidades médias.

Neste primeiro capítulo, Henríquez apresenta ao leitor, o que me parece ainda mais importante para os estrangeiros, o que amplia as possibilidade de leitura do seu livro: o quadro em que se tem delineado a questão ambiental no Chile, frisando tanto condicionantes econômico-políticas como o marco jurídico e os planos de trabalho, com destaque para o "Chile Sustentable", de 2003, e para a "Política Nacional de Desarrollo Urbano, Ciudades Sustentables y Calidad de Vida", de 2013.

As relações entre desenvolvimento sustentável e cidade sustentável ganham atenção de Henríquez, que remarca enfoques possíveis e coteja as posições de vários autores, elegendo ele mesmo três aspectos que considera essenciais para se alcançar uma cidade sustentável: 1) que ela seja compacta, 2) que seus usos de solo sejam mistos e 3) que baixos níveis de pobreza, combinem-se com diversidade econômica e pouco uso do automóvel.

Realiza uma retrospectiva histórica que auxilia a conceituar cidade e, em seguida, destaca elementos para se parametrizar cidade média, visto que uma particularidade importante do livro de Cristian é seu foco nestas cidades. Isso é importante num período em que, tendo em vista a complexidade dos problemas nas grandes cidades, os estudos metropolitanos imperam e, muitas vezes, impõem-se para a compreensão de outras realidades urbanas.

A (in)sustentabilidade da urbanização no Chile é tratada, trazendo-se informações sobre a rede e a hierarquia urbana para apresentar um quadro geral, no plano interurbano e no que concerne aos espaços urbanos, dando-se destaque ao processo de fragmentação social das cidades, buscando mostrar como as recentes políticas econômicas no país levaram à ampliação das desigualdades socioespaciais e, incluso, à segregação residencial, o que traz impactos tanto para a justiça social como para a justiça ambiental, o que, sem dúvida, são possíveis retrocessos 
quando se pensa na direção de uma cidade sustentável.

O crescimento rápido das cidades médias no Chile e as dinâmicas já expostas pelo autor para tratar da urbanização no país têm levado a que estas cidades, ao contrário do que se poderia supor ou desejar, já apresentam condições econômicas, sociais e ambientais que pouco corresponderiam a maior potencial de sustentabilidade, o que requer atenção rápida e eficaz.

A aproximação com a Ecologia Urbana é o modo encontrado por Henríquez para abordar os impactos ambientais sobre a urbanização e, sobretudo, para reconhecer os padrões espaciais das cidades latino-americanas como modo de compreender melhor suas estruturas espaciais. Incorpora em seu texto, o excelente esquema de Borsdorf (2003), adaptando-o, mostrando em seguida, num excelente quadro, as diferenças entre a cidade compacta e a dispersa, no que respeita às pressões e impactos sobre a sustentabilidade.

É objeto de trabalho, no segundo capítulo, nomenclaturado "La Evolución del crecimento de Chillán y Los Ángeles", a evolução do crescimento das duas cidades localizadas na VIII Região chilena, a de Biobío, estudadas pela equipe de Federico Arenas e Cristian Henríquez Ruiz, da Pontifícia Universidad Católica de Chile, no âmbito da Rede de Pesquisadores sobre Cidades Médias - ReCiMe.

Uma caracterização geral delas é efetuada e são expostos aspectos físicos e geográficos, os quais são valorizados para explica-las. A evolução histórica delas em muito auxilia o leitor a perceber como ocorreram suas estruturações econômicas e espaciais.

Por meio do estudo das mudanças no uso do solo e na cobertura vegetal, utilizando-se uma matriz de conversão, o autor elabora, ainda, três representações cartográficas para cada uma das duas cidades. Elas comunicam, de modo didático, tanto a expansão do tecido urbano, como os principais usos de solo rural destes municípios para, na seção seguinte deste segundo capítulo, o autor tratar das mesmas dinâmicas no "interior" do espaço urbano.

As novas áreas de expansão urbana das duas cidades ganharam relevância no livro, justamente em função da posição externada pelo autor de que a sustentabilidade urbana dependeria do padrão concentrado e não do disperso, o que esta expansão gera e estimula.

As fotos, gráficos, imagens de satélites propiciam uma ampliação da capacidade do leitor de apreender os fenômenos em tela, tanto porque complementam o texto por meio de outras linguagens, como pelo fato de o sintetizarem.

No terceiro capítulo, denominado "Modelación del do crecimiento de Chillán y Los Ángeles", a proposta do autor começa a ganhar contornos mais nítidos, primeiramente, com a análise e não apenas descrição ou sistematização dos padrões espaciais de crescimento delas.

Henríquez mostra a área destinada à expansão urbana; correlaciona os padrões desta expansão tomando como referência o centro das duas cidades; compara-a ao crescimento demográfico; apresenta informações sobre a evolução econômicas delas, por ramos de atividades. Expõe estas múltiplas relações com dados precisos e amplos, diversos e em evolução no tempo, além de representá-los em gráficos que comunicam de modo muito didático as dinâmicas em curso.

Neste mesmo capítulo, ele se dedica à análise da paisagem, tomando-a no seu sentido "físico" e "social" (sendo fiel aqui aos adjetivos adotados pelo autor), mostrando que a cidade que se torna mais dispersa tende a ser mais fragmentada em função, incluso, de usos mais atomizados de seu território e da área rural que a circunda.

No que concerne ao primeiro aspecto da paisagem, toma como referência os parques, por exemplo, mas também destaca os usos de solo agrícola e pastoril, e, ao analisar as informações vai indicando as diferenças entre Los Ángeles e Chillán. Isso nos revela a importância da comparação, já indicada pelos geógrafos franceses, como um princípio de método para o nosso campo científico.

Relativamente ao segundo aspecto, já inicia seu enfoque frisando que uma cidade mais fragmentada é menos sustentável, pois aumentam fragmentos físicos e a distância 
social entre seus moradores, gerando efetivas polarizações socioespaciais.

Considerei muito interessante os indicadores que propôs para avaliar as forças motrizes da fragmentação urbana: número de parques, riqueza, poder, status, conhecimento e território, expresso este último pela relação entre habitantes e residências. Adotou, para cada um deles, variáveis relevantes e os mensurou no decorrer do tempo, entre 1982 e 2012.

Tais esforços levam o autor, a discutir, ao final do capítulo se tais cenários indicam crescimento urbano futuro. Em outras palavras, aqui como em várias partes do livro, ele vem do passado para explicar o presente, buscando abrir possibilidades para ler os anos que virão, fazendo simulações, organizando esquemas e formulando projeções.

Os mapas estocáticos de uso simulado do solo para 2048; os de avaliação multicritérios deste uso para 2013; e os de simulação do uso e cobertura vegetal para 2013, 2018, 2028 e 2048 são estimulantes para a imaginação geográfica, adotando aqui a valiosa expressão tão usada por David Harvey para distinguir a sensibilidade que os geógrafos têm e devem estimular, como o faz Cristián Henríquez Ruiz.

A "Evaluación Ambiental del Impacto de Chillán y Los Ángeles" é o tema do quarto capítulo, em que o autor começa pelas repercussões da urbanização sobre o clima local para modelizar, em seguida, as ilhas de calor urbano e verificar as mudanças na intensidade delas.

Os efeitos da impermeabilização dos solos são, igualmente, tratados, pois efetivamente têm grande importância para a avaliação da sustentabilidade urbana.

O autor enfoca na última parte do capítulo as dinâmicas de perda de solo, em função do processo de produção do espaço urbano.

Para todas estas dinâmicas, são oferecidos dados diversos e precisos, tanto quanto são elaborados tratamentos estatísticos, gráficos e cartográficos, vários deles com grau elevado de sofisticação, sem que o texto se torne difí- cil demais para os que não dominam formas avançadas de tratamento das informações.

A partir de uma pergunta - " ¿Son Sustentables los Patrones de Crecimiento Urbano de las Ciudades Medias?" - o quinto capítulo é desenvolvido. Para respondê-la, ele busca articular aspectos que foram tratados nos quatro capítulos anteriores, bem como utiliza-se, novamente, da ferramenta da comparação, inclusive com outras cidades do mundo, como no gráfico em que compara as duas estudadas neste livro, com cidades chinesas, mostrando que naquelas à medida que a expansão urbana ocorre amplia-se a distância das principais vias de circulação, o que traz, a meu ver, diminuição efetiva da acessibilidade e, por conseguinte, da equidade territorial.

A planificação e a gestão urbanas também são trabalhadas neste capítulo do livro e são oferecidos modelos esquemáticos, de boa qualidade, de prospecção e simulação do crescimento urbano.

"Los desafíos para la sustentabilidad urbana" é o interesse de Henríquez no capítulo 6 que tem caráter conclusivo nesta obra. Ele joga luz, sobre dois pontos de grande importância: os desafios e as implicações territoriais do modelo e as metas para a sustentabilidade e planificação urbana.

As articulações entre o social, o econômico e o ambiental acabam se evidenciando claramente neste último capítulo, mostrando que, se o leitor supõe que este é um livro estritamente técnico, visto que voltado à modelização, engana-se. Ele é, igualmente, um livro político, no melhor sentido que este a palavra 'político' tem, porque trata das forças que se interpõem na direção da sustentabilidade urbana e, portanto, dificultam o alcance justiça ambiental e da equidade socioterritorial.

Convido o leitor, ao final, a apreciar a bibliografia, pois, de um lado, ela mostra que a pesquisa que gerou este livro é de qualidade, pela variedade de referências, tanto em termos de países de origem dos autores, quanto de campos científicos a que se filiam. De outro lado, tais referências são valiosas para aqueles que desejam se tornar experts 
no tema, aprofundando aspectos já tão bem desenvolvidos por Henríquez.

Sem dúvida, ao percorrer os seis capítulos que compõem este livro, vejo o quanto ele revela a indissociabilidade entre ações da sociedade e alterações dos processos e dinâmicas naturais. Por isso, Henríquez contribui para mostrar o quanto o mundo contemporâneo têm propiciado e, mais que isso, exigido que o tempo histórico se acelere, levando a um aprofundamento das contradições entre ele e o tempo geológico, aquele que rege e expressa os processos e as dinâmicas da $\mathrm{Na}$ tureza. Por esta razão, pesquisa e ação devem se unir para enfrentar o que se apresenta a nós, como cientistas e como cidadãos, que são os desafios na direção da sustentabilidade, nos termos desejados nesta obra. 